\title{
Evaluating Saudi Nursing Students' Knowledge and Attitudes toward Cancer Pain Management: Implications for Nursing Education
}

\author{
Dhuha Y. Wazqar, PhD, RN \\ Department of Medical Surgical Nursing, Faculty of Nursing \\ King Abdulaziz University, Jeddah, Saudi Arabia
}

\section{Correspondence \\ Dr. Dhuha Y. Wazqar \\ Department of Medical Surgical Nursing \\ Faculty of Nursing, King Abdulaziz University \\ P. O. Box 24828, Jeddah 21551 \\ Saudi Arabia \\ e-M: dwazger@kau.edu.sa \\ Submission: 11 Nov. 2019 \\ Accepted: 03 Dec. 2019}

\section{Citation}

Wazqar DY. Evaluating Saudi nursing students' knowledge and attitudes toward cancer pain management: implications for nursing education. JKAU Med Sci 2019; 26 (2): 61-70. DOI: 10.4197/Med.26-2.7

Copyright: (T) The Author(s), YEAR. Publisher. The Journal of King Abdualziz University - Medical Sciences is an Official Publication of "King Abdulaziz University". It is an open-access article distributed under the terms of the Creative Commons Attribution Non-Commercial License, which permit unrestricted non-commercial use, distribution, and reproduction in any medium, provided the original work is properly cited.

\begin{abstract}
Ineffective pain management has been recognized as a major problem faced by many patients with cancer. There is a lack of emphasis on cancer pain management in the undergraduate nursing curriculum which is one part of this problem. A descriptive cross-sectional study was carried out with a convenience sample of 135 nursing students at two universities in Jeddah, Saudi Arabia, to evaluate students' current knowledge and attitudes toward cancer pain management. Data were collected using Pain Management Principles Assessment Test and Nurses' Pain Management Attitudes Survey. The data were analyzed using IBM Statistical Package for the Social Sciences version 22 , and $P<0.05$ was interpreted as significant. Descriptive and inferential statistics and Pearson correlations were performed. Nursing students have insufficient knowledge $(11.4 \pm 2.92)$ and negative attitudes $(68.8 \pm 5.75)$ toward cancer pain management. None of the nursing students achieved complete, correct responses (31 or 100\%) in the knowledge test. Students had poor knowledge regarding areas of pain physiology and assessment, pharmacologic and nonpharmacologic pain management such as cutaneous stimulation. A weak positive significant relationship between students' knowledge and attitudes was also found $(r=0.225, P=0.009)$. Continued work is required to develop specific strategies to effectively teach nursing students and enhance their knowledge and attitudes toward cancer pain management.
\end{abstract}

\section{Keywords}

Attitudes; Cancer pain management; Knowledge; Nursing students; Nursing education 


\section{Introduction}

$R$ elieving cancer pain is a global health problem that requires immediate attention ${ }^{[1]}$. The British Pain Society has defined cancer pain as a complex and multi-dimensional experience including acute and chronic pain that reflects both damage to the body and the body's response to the damage ${ }^{[2]}$. Cancer pain is caused by tissue injury due to cancer itself, diagnostic procedures, or cancer treatment modalities such as surgery, radiation therapy, and chemotherapy ${ }^{[3]}$. Moderate to severe pain is a common distressing symptom throughout the cancer trajectory, and the prevalence of this pain increases throughout the course of illness ${ }^{[4]}$. Seventy percent of the terminally ill cancer patients, and $30 \%$ to $50 \%$ of patients receiving cancer treatment suffer from chronic pain whereas pain persists for $33 \%$ of cancer survivors ${ }^{[5,6]}$. A study conducted on cancer patients recruited from oncology units of a university hospital in Riyadh, Saudi Arabia, on palliative care service found that $51 \%$ of participants experienced moderate to severe pain ${ }^{[7]}$.

Unmanaged cancer pain can negatively impact the quality of life of patients, families, and caregivers including mental distress (depression and anxiety), sleep disturbance, social isolation, functional disability, and immobility ${ }^{[3]}$. Also, it increases the burden on healthcare providers and hospitals due to prolonged duration of hospitalization, increased re-admission rates, and increased healthcare expenses ${ }^{[8]}$. Adequate cancer pain management is the cornerstone of symptom management for cancer patients ${ }^{[4]}$. Although World Health Organization (WHO) guidelines and recommendations for cancer pain management were issued more than twenty years ago, a considerable amount of evidence suggests that the management of cancer pain is often sub-optimal in Saudi Arabia ${ }^{[7,9]}$.

There are many problems that hinder effective cancer pain management in Saudi Arabia. Factors related to health care providers' knowledge and attitudes seem to play a significant role. Previous studies have demonstrated that Saudi nurses lack adequate knowledge and proper attitudes for managing cancer pain effectively leaving many patients to suffer ${ }^{[10,11]}$. Researchers also reported suboptimal cancer pain management by nurses is due to poor pain assessment, inadequate knowledge, and negative attitudes together with insufficient guidance from cancer pain consultants in Saudi hospitals ${ }^{[12,13]}$. Another study explored pain knowledge and attitudes of 255 healthcare providers and found that the nurses abstained from giving opioids to their patients because of a fear of respiratory depression and addiction ${ }^{[14]}$. Furthermore, a lack of knowledge among Saudi nurses about the concepts related to cancer pain management strategies and the non-pharmacological and pharmacological interventions to manage it was noted ${ }^{[10]}$. This lack of knowledge and the negative attitudes demonstrated by nurses from the previous studies results from deficiencies in their formal training and continuing professional development.

Prior research has suggested that barriers to effective cancer pain management might be due to a lack of training specific to cancer pain and pain management ${ }^{[15,16]}$. This has subsequently led to negative attitudes toward cancer pain management due to fear of liability, unfamiliarity, and anticipated risks that might include respiratory depression, dependence, and addiction ${ }^{[11,15]}$. Nurses with insufficient cancer pain management training/education cannot deliver proper care to patients that are suffering from painparticularly in oncology units where cancer pain management is an important element of nursing care $^{[16]}$.

There is limited literature on the knowledge and attitudes of nursing students during their undergraduate training in Saudi Arabia. This includes a lack of insight into effective management of cancer pain during clinical training. In Saudi nursing programs, cancer pain and pain management are normally discussed in different courses including physiology, pharmacology, and medical-surgical nursing. There is also a lack of formal pain management and cancer nursing courses in undergraduate nursing curriculum in colleges. This can hinder graduate nurses' ability to properly manage and assess cancer pain. The effect of this on the level of knowledge and attitudes of nursing students towards cancer pain management has never been examined in Saudi Arabia. A literature search identified only one study conducted among Saudi medical students ${ }^{[17]}$. It is therefore necessary to understand nursing students' foundation of cancer pain management and attitudes that are then translated into clinical practice. The purpose of this study was to evaluate the current knowledge and attitudes of Saudi nursing students who have passed physiology, pharmacology, and medical-surgical nursing core courses focused on cancer pain and pain management contents. The study details the strengths and weaknesses of nursing students regarding cancer pain 
management. It can also help modify undergraduate nursing programs for an improved emphasis on cancer nursing and pain management courses.

\section{Methods}

A descriptive cross-sectional design was used to evaluate the knowledge and attitudes of 135 female nursing students (convenience sample) toward cancer pain management across two universities in Jeddah City, Saudi Arabia. The target population was final year nursing students registered in the selected universities. Approximately 207 nursing students who met the inclusion criteria enrolled in the universities. The two universities have the same nursing academic systems, policies, and procedures and follow the Saudi Arabian Ministry of Education accreditation of higher education. The selection of the participants in this study was based on the following criteria: must be willing to participate; must be registered students at one of the universities; must have completed the third year of their undergrad nursing study (as these students are likely to be finishing the most important part of their clinical training); and must have passed the physiology, pharmacology, pathology, and medicalsurgical nursing courses.

Nursing students' knowledge was assessed by the Pain Management Principles Assessment Test (PMPAT) ${ }^{[18]}$. This instrument is a multiple-choice quiz (31 questions) with four responses for each question. This was used to assess pain management knowledge regarding pharmacology, physiology, and pain characteristics such as principles of management, tolerance, physical dependence, and addiction. The PMPAT scores ranged from zero to 31 and were then calculated to a percentage score from zero to 100 with lower scores indicating that many questions were incorrectly answered. The instrument validity was confirmed among 28 nursing students using a pre and post-test technique before and after taking a pain management module $(t=6.76, \mathrm{P}<0.001)^{[18]}$. In addition, the reliability of the instrument $(r=0.84, P<$ 0.001 ) was established using test-retest reliability with a delay of one week ${ }^{[18]}$. More than $60 \%$ is considered a passing score on the PMPAT.

The Nurses' Pain Management Attitudes Survey (NPMAS) assessed attitudes of nursing students toward cancer pain management in this study. The NPMAS is a 25-item tool developed by McMillan et al. ${ }^{\{19\}}$ and rated on a 4-point Likert scale (strongly agree, agree, strongly disagree, and disagree). A lower score indicates more attitudinal problems among nursing students. The questionnaire involves items on pain assessment and its goals, the use of narcotics, scheduling analgesics, non-pharmacologic interventions of pain, and some misconceptions about cancer pain management. Validity was further confirmed by comparison of nurses' scores at different levels of expertise that included senior pain experts, graduate students, oncology nurses, new graduates, and students. Cronbach's alpha of the NPAS was adequate $(P=0.70)^{[19]}$.

Permission to use PMPAT and NPMAS tools was obtained. The investigator used the English version of the questionnaires because English is the official language of education at the nursing colleges in Saudi Arabia. Finally, the demographic data collected included age, previous training or workshops/lectures/ advanced courses of cancer pain management outside the university ("Yes" or "No"), and previously cared for cancer patients in pain ("Yes" or "No").

Ethical approval was obtained from the universities' research ethics committees prior to data collection. One condition was not mentioning the names of the universities in any conference presentations or publication to protect their reputations among other competitive nursing colleges in Saudi Arabia. The data were collected 11-30 March 2018. A brief description of the study was provided to the students noting that there were no benefits and or risks to nursing students for participating. Students who agreed to be involved in the study were asked to sign a written consent form. During scheduled class time, study questionnaires were given to the participants who were asked to read the information and then complete the questionnaires separately without the assistance of colleagues or textbooks. The researcher was present in the classroom to respond to any questions or concerns related to the study. Questionnaires took on average 25 minutes for participants to complete. The questionnaires were collected at the end of the class by the investigator and kept in a locked drawer in her office and were used only for research purposes. Soft and electronic copy data were also saved on a high-quality hard drive that was encrypted and protected with a password and kept in a safety cabinet. There were no personal identifiers on the questionnaires. IBM Statistical Package for the Social Sciences (SPSS) version 22 (IBM Corp, Armonk, NY) was used for statistical analysis. Means, standard deviations (SD), percentages, and frequencies were used to describe the participants' characteristics 
and their answers to the questions in the survey. Also, the independent t-test and Pearson correlations were used. Cronbach's alpha reliability analysis was performed for the tools to identify internal consistency. The level of significance was set at a P-value of $<0.05$ in all analyses. If students did not answer any question $(\mathrm{N}=32)$, this question was coded as an incorrect answer, comparable to how it would be marked in the classroom test situations.

\section{Results}

Of the 207 nursing students currently in their final year of nursing asked to participate in this study, 135 completed the questionnaire (response rate $65.2 \%$ ). Forty-two (20.3\%) students decided not to participate by leaving the class before questionnaire distribution, and $30(14.5 \%)$ students did not complete the PMPAT and NPAS portions. The mean age of the participants was $21.4 \pm 0.96$ years ranging from 20 to 25 years. Fortysix percent $(N=62)$ of the students had participated in cancer pain management advanced courses/ workshops/ lectures/training outside the universities, whereas 54\% ( $\mathrm{N}=73)$ had no training/advanced courses beyond that offered in their nursing programs. Eighty-six (63.7\%) students cared for cancer patients in pain previously during their clinical training.

The PMPAT total correct item score ranged from 5 (16\%) to $22(71 \%)$ with a total mean correct answer of $11.4 \pm 2.9$ out of 31 items (total score if all questions answered correctly), and the rate of correct answer ranged from $5 \%$ (question 7) to $84 \%$ (question 8 ). This mean score indicated that participants on average answered only $37 \%$ of the questions correctly. None of the participants achieved complete and correct responses ( 31 or $100 \%$ ). If $>60 \%$ was considered as the passing score, then $1.5 \%(\mathrm{~N}=2)$ of participants passed this test (Table 1).

The results show that many questions were answered incorrectly-mainly those related to areas of pain physiology and non-pharmacologic pain management: (1) blood level of analgesia, (2) acute pain symptoms, (3) theory of gate control, (4) C-fibers and pain sensation, and (5) use of cutaneous stimulation as

Table 1. Frequency and percentage of knowledge test scores

\begin{tabular}{|c|c|}
\hline Scores & Frequency (\%) \\
\hline More than $60 \%$ & $2(1.5 \%)$ \\
$50 \%-60 \%$ & $9(6.7 \%)$ \\
Less than 50\% & $124(91.8 \%)$ \\
\hline
\end{tabular}

a non-pharmacologic technique as presented in Table 2. Concerning pharmacologic management, around $62 \%$ $(\mathrm{N}=83)$ of the students accurately defined tolerance and recognized that Meperdine has severe central nervous system side effects, and $45.9 \%(N=62)$ of the students stated the action of naloxone. They knew the use of combined analgesics achieves cancer pain control, but only $9 \%(\mathrm{~N}=12)$ of the students recognized that the preferred route of pain medications for cancer patients was oral; $14 \%(N=19)$ of the participants knew that Methadone as a narcotic pain medication has the longest duration of action. Interestingly, most students agreed that the patient is the only reliable source for pain reporting $(60 \%, \mathrm{~N}=81)$.

The mean NPAS score was $69 \pm 5.75$ on a test with scores ranging from 25 to 100 . The participants' scores ranged from $49 \%$ to $83 \%$ of students reporting adequate attitudes toward cancer pain management. Item analysis of the NPAS showed that most nursing students agreed that (1) continuous assessment of medication effectiveness and pain is a critical step to provide good pain management, (2) patients should have control over their pain medications schedule, (3) no expression of pain does not indicate absence of pain, (4) nurse should contact the physician, if patients still complain of pain after taking pain medications, and (5) diversion and distraction may reduce patients' pain level. Students had low scores in using of aroundthe-clock dosing and as-needed medications because of the worry of dependency and risk of respiratory depression (item 12). Additional findings encompassed negative attitudes to keeping their patients in painfree conditions (item 14), and when it is appropriate for cancer patients to ask for other pain medications (item 25) (Table 3).

There was a significant weak positive correlation between knowledge and attitudes of nursing students toward cancer pain management $(r=0.225, p=0.009)$. This suggested that nursing students with more information about cancer pain and its management had more positive attitudes than those with a low level of knowledge. Age was not correlated to students' knowledge $(r=0.046, p=0.595)$ or attitudes $(r=-0.157$, $\mathrm{P}=0.069)$ mean score. Independent t-test was also used to examine study variables by their demographic characteristics. There were no significant differences identified in the students' knowledge or attitudes mean scores in term of previous cancer pain management training/advanced courses and previously cared for cancer patients in pain (Table 4). 
Evaluating Saudi Nursing Students' Knowledge and Attitudes toward Cancer Pain Management...

Table 2. Frequency of correct answers by participants in the knowledge test

\begin{tabular}{|c|c|c|}
\hline \multirow{2}{*}{ Questions } & \multicolumn{2}{|c|}{ Correct Responses } \\
\hline & $\mathbf{N}$ & $\%$ \\
\hline 1. Patients with cancer who suffer from pain (percentage) & 38 & 28.1 \\
\hline 2. Patients with cancer who experience pain for more than a month (percentage) & 41 & 30.4 \\
\hline 3. The nurse should call the physician if patients continue to have pain & 49 & 36.3 \\
\hline 4. Route of analgesics administration for cancer patients & 12 & 9 \\
\hline 5. At what level is it appropriate for cancer patient to ask for additional pain medication & 21 & 15.6 \\
\hline 6. The accurate and reliable judge of the intensity of pain & 81 & 60 \\
\hline 7. Patients who are receiving narcotic analgesics become addicted (percentage) & 7 & 5.2 \\
\hline 8. Analgesics mechanism of action & 113 & 83.7 \\
\hline 9. Cutaneous stimulation can treat which type of pain & 25 & 18.5 \\
\hline 10. Principles underlying narcotic administration in advanced cancer patients & 38 & 28.1 \\
\hline 11. Common chronic pain symptoms & 67 & 49.6 \\
\hline 12. Methadone has the longest duration of action & 19 & 14 \\
\hline 13. Acute pain is usually associated with increased temperature and caloric requirement & 41 & 30.4 \\
\hline 14. C-Fibers are accountable for the aching and dull pain sensation & 27 & 20 \\
\hline 15. The substantia gelatinosa is responsible for "gating" & 55 & 40.7 \\
\hline 16. Pain is modulated by opiate receptors & 79 & 58.5 \\
\hline 17. Pain is related to a decrease level of the analgesic in blood & 26 & 19.3 \\
\hline 18. Goal of pain management & 32 & 23.7 \\
\hline 19. Overall quality of life is the primary factor to consider for cancer patients & 73 & 54.1 \\
\hline 20. Factors which impact expression of pain & 96 & 71.1 \\
\hline 21. Naloxone mechanism of Action & 62 & 45.9 \\
\hline 22. Research indicates nurses under-medicate and physicians under-prescribe & 14 & 10.4 \\
\hline 23. Meperidine has more neurotoxicity than Morphine & 83 & 61.5 \\
\hline 24. Intravenous drip is the method of administration of steady-state analgesia & 36 & 26.7 \\
\hline 25. Steady-state analgesia primary benefit & 63 & 46.7 \\
\hline 26. Variables which affect nursing decision & 34 & 25.2 \\
\hline 27. Patient has the most control over the schedule of pain management & 33 & 24.4 \\
\hline 28. Tolerance (definition) & 83 & 61.5 \\
\hline 29. Backrub with heating pad is a cutaneous stimulation example & 62 & 45.9 \\
\hline 30. Examples of interruption & 67 & 49.6 \\
\hline 31. Managing pain for patients with metastatic cancer using narcotic, anti-inflammatory & 62 & 45.9 \\
\hline
\end{tabular}

PRN: Pro re nata (as needed)

\section{Discussion}

The findings of this study showed that knowledge and attitudes of our nursing students towards cancer pain management were sub-optimal. A mean score of $37 \%$ on the knowledge test and a mean score of $69 \%$ on the attitudes test were seen, suggesting poor knowledge and negative attitudes towards cancer pain management. This is well below failing the acceptable level (80\%) for graduate nursing students and below what we expected. This indicates an obvious problem in the nursing curriculum in terms of cancer pain management ${ }^{[20]}$. Similarly, Iranian and Jordanian nursing students reported significantly lower levels of knowledge and attitudes toward cancer pain management ${ }^{[21,22]}$. Researchers found that Jordanian and Iranian nursing students' mean correct answer scores on the knowledge test were $34.1 \%$ and $37.8 \%$. Another study conducted in Saudi Arabia also found a similar finding: that the knowledge of cancer pain management among most nurses working in oncology units is generally poor ${ }^{[12]}$. A higher PMPAT score of $63 \%$ was seen among fourth-year nursing students in the Nursing College at South Florida University, USA ${ }^{[16]}$. Nursing students' low scores in this study may be due to the scarce time that has been devoted to pain assessment and management in the nursing curricula. Such a low score requires the inclusion of cancer pain assessment and management education in nursing curricula to improve the knowledge of our nursing students, which may lead to more positive attitudes toward cancer pain management. 
Evaluating Saudi Nursing Students' Knowledge and Attitudes toward Cancer Pain Management...

Table 3. Frequency of participants with positive responses to attitudes questions

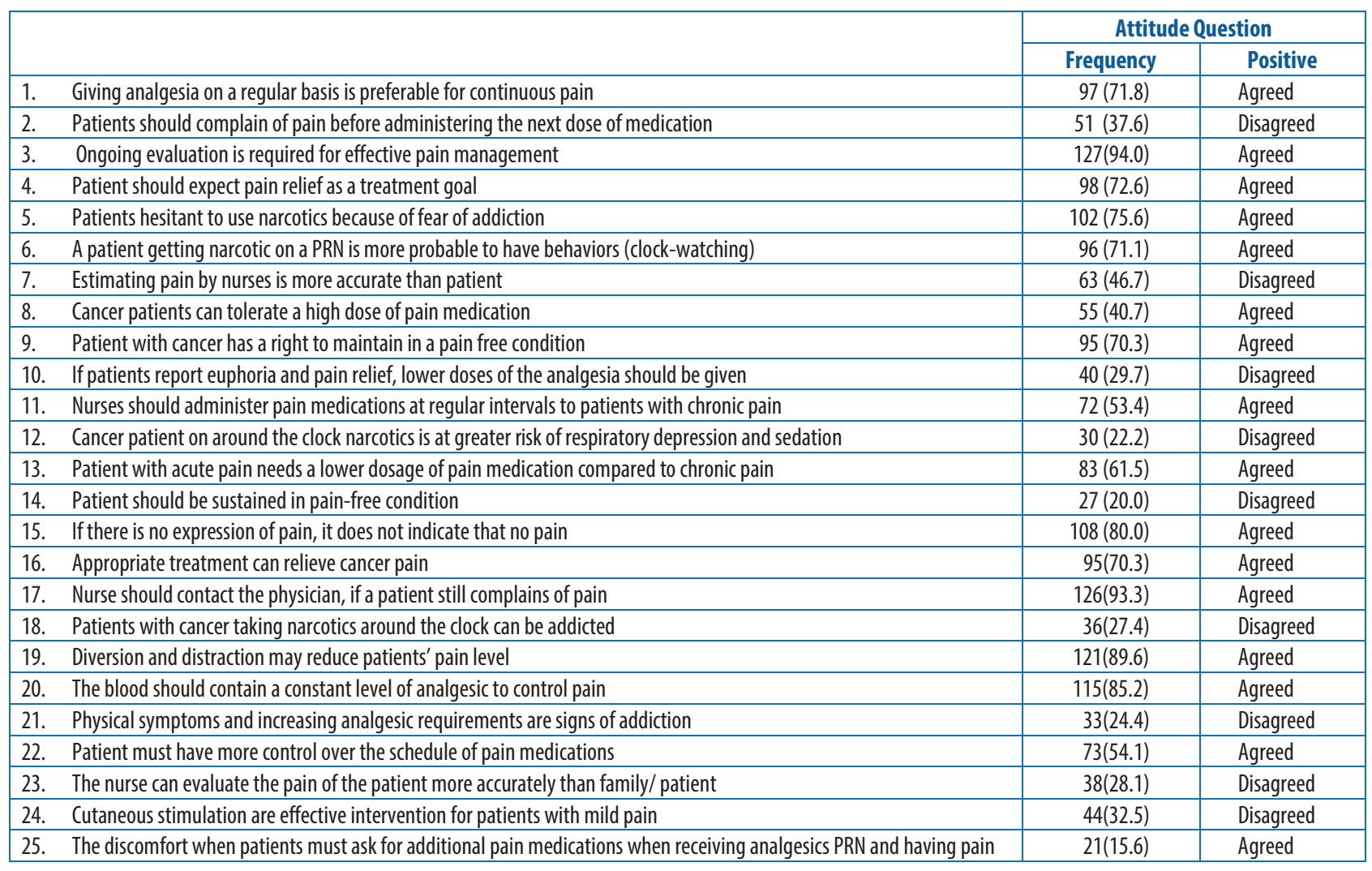

Table 4. Differences of nursing students' knowledge and attitudes mean score based on cancer pain education and caring for cancer patients in pain

\begin{tabular}{|c|c|c|c|c|}
\hline Variables & Mean \pm SD & t-value & df & P-value \\
\hline Knowledge (PMPAT) & $11.40 \pm 2.92$ & & & \\
\hline $\begin{array}{l}\text { Previous training/advanced courses } \\
\text { Yes }(N=62) \\
\text { No }(N=73)\end{array}$ & $\begin{array}{l}11.06 \pm 2.78 \\
11.68 \pm 3.02\end{array}$ & 1.23 & 133 & 0.220 \\
\hline $\begin{array}{l}\text { Previously cared for cancer pain in pain } \\
\qquad \begin{array}{l}\text { Yes }(N=86) \\
\text { No }(N=49)\end{array}\end{array}$ & $\begin{array}{l}11.32 \pm 2.84 \\
11.03 \pm 2.34\end{array}$ & 1.12 & 132 & 0.137 \\
\hline Attitudes (NPMAS) & $68.80 \pm 5.75$ & & & \\
\hline $\begin{array}{l}\text { Previous training/advanced courses } \\
\text { Yes }(N=62) \\
\text { No }(N=73)\end{array}$ & $\begin{array}{l}69.00 \pm 5.29 \\
68.60 \pm 6.14\end{array}$ & -0.39 & 133 & 0.691 \\
\hline 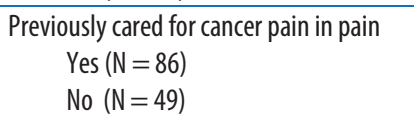 & $\begin{array}{l}68.65 \pm 6.19 \\
68.32 \pm 5.41\end{array}$ & -0.34 & 131 & 0.562 \\
\hline
\end{tabular}

SD: Standard deviation; df: Degrees of freedom; PMPAT: Pain Management Principles Assessment Test; NPAS, Nurses Pain Management Attitudes Survey 
Many areas that were commonly missed in this study were questions related to the knowledge that need to alert universities and academic educators to their deficiencies in the nursing programs. Questions like the preferred route of narcotic analgesics and principles of administration, the action of naloxone, methods of steady-state analgesia, and Meperdine side effects had a less than $60 \%$ pass rate. Nursing students had negative attitudes regarding cancer patients taking around-the-clock narcotics and the ability of these patients to tolerate a high dose of narcotic analgesia without side effects. Nursing students did not recognize that respiratory depression and sedation are rare in cancer patients with high narcotic tolerance. These findings were similar as in earlier research; obviously, little progress has been made in this area over the past 15 years ${ }^{[1,16,20]}$. This also revealed that most nursing curricula had no or little cancer pain management contents, and nursing students were not well-trained to apply proper pain management interventions.

Areas where most students had high levels of cancer pain management knowledge and positive attitudes included knowing who can best judge cancer patients' pain, understanding analgesia mechanism of action, and questions about factors which impact expression of pain. This might indicate that nursing students may have strong theoretical understanding of general cancer pain concepts, but they do not apply this knowledge properly in their clinical practice.

The study findings also show that there was a weak but significant and positive correlation between knowledge and attitudes of nursing students toward cancer pain management. Students who had a low score on the knowledge questionnaire had a similarly low score on the attitudes' questionnaire as well. These findings concur with previous studies among nursing students and oncology nurses when researchers found a weak/moderate correlation between nursing students' knowledge and attitudes $(P<0.01)^{[16,23]}$. There has been some consistency between similar questions on the attitudes and knowledge questionnaires. Most nursing students in this study indicated that additional as-needed pain medication should not be given until pain returns on the knowledge test. Students also confirmed that the patient with cancer should complain of pain before taking the next dose of pain medication on the attitude questionnaire. An exaggerated fear of narcotic-related adverse reactions and addiction was noted in this study. Healthcare providers' fear regarding addiction is one of the barriers to effective cancer pain management ${ }^{[4]}$. These addiction myths are properly due to insufficient knowledge about opioid analgesics and their uses. Many nursing students also accurately defined tolerance on the knowledge questionnaire, and a large number of students knew that it is very unlikely that cancer patients will become addicted to pain medication on the attitudes questionnaire. Therefore, we noted that the scores of knowledge and attitudes appear to be related in terms of addiction. These consistencies may suggest that the knowledge of nursing students affects their attitudes toward cancer pain management practices.

Although participation in workshops and courses on cancer pain management and previously cared for patients in pain has been shown to have a significant impact on nursing students' knowledge and attitudes toward cancer pain management in earlier studies ${ }^{[12,22,24]}$, this study did not confirm this. One study has examined pain management and shares similar findings with this study ${ }^{[25]}$. This might be due to inadequate preparation in continuing nursing education. Further research studies may require groups to investigate the relationships between cancer pain management knowledge and attitudes scores as well as the demographic characteristics among nursing students to better explain the relationships.

There are several limitations and strengths to be taken into consideration in this study. The study used a cross-sectional design, and therefore cannot establish causal or temporal relationships between the variables. Interventional studies are wanted to assess the effect of cancer pain management courses/programs on nursing students' knowledge and attitudes. Using an English survey among Arabicspeaking people is another limitation in this studythis may affect their understanding of the questions. Nevertheless, this study adds to our understanding of the psychometric properties of the instruments used within the context of Saudi nursing students. A self-administered questionnaire does not allow for investigation of the nursing students' actual practice in the management of cancer pain. Therefore, in future studies, collecting data through an observational approach may be more valuable. This is the first study to ask these specific questions in Saudi Arabia, which prevents direct comparisons to prior work. Studies conducted internationally have been used, but these may have a slightly different curriculum or education. The good response rate of the nursing students and 
the high internal consistency values of the instruments in this study emphasize that the findings give a clear picture about the current status of nursing students in Saudi Arabia. It can be also extrapolated to the knowledge and attitudes of nursing students in other cultures and developing countries regarding cancer pain management due to the curriculum similarity of nursing colleges.

\section{Conclusions}

The purpose of this study was to evaluate the current knowledge and attitudes regarding cancer pain management among Saudi nursing students. The results indicate that there were severe knowledge deficits and negative attitudes about cancer pain management among our nursing students. Inadequate knowledge of cancer pain management in the baccalaureate nursing curriculum could have a negative impact on continuing education when nurses graduate, which consequently impact on the pain management of cancer patients. This study may provide academic educators and decision-makers with insight into the significance of developing a cultural nursing curriculum involving more information on cancer pain and its management. There is an urgent need to incorporate novel teaching strategies and put more emphasis on pain management and pharmacology as well as practical skills while nursing students are in clinical placements. Topics/courses addressing cancer pain physiology, pharmacology, and nonpharmacologic pain management strategies as well as concepts such as addiction, tolerance, and dependence in the curriculum would be also useful in enhancing the nursing students' knowledge and attitudes as well as the patients' quality of life. Moreover, clinical instructors need to emphasize the importance of regular pain assessment and management practice in everyday practice. Nursing faculties can change clinical practice and how patients with cancer receive pain management. The study findings can serve as baseline data for use by educators, nurse researchers, oncology nurses, and nursing administrators to improve the field.

\section{Conflict of Interest}

The author has no conflict of interest.

\section{Disclosures}

The author did not receive any type of commercial support either in forms of compensation or financial for this study. The author has no financial interest in any of the products or devices, or drugs mentioned in this article.

\section{Ethical Approval}

Obtained.

\section{Acknowledgments}

The author would like to thank Ebaa Marrow, Reem Hassan, and Amal Bahithem, for their help in collecting data from the study participants.

\section{References}

[1] Phillips JL, Lovell M, Luckett T, Agar M, Green A, Davidson P. Australian survey of current practice and guideline use in adult cancer pain assessment and management: the community nurse perspective. Collegian 2015; 22(1): 3341.

[2] [No authors listed]. Cancer pain management. The British Pain Society. Accessed May 21, 2019. <https://www. britishpainsociety.org/static/uploads/resources/files/ book_cancer_pain.f/>.

[3] [No authors listed]. Cancer pain. International Association for the Study of Pain (IASP). Accessed May 21, 2019. <https://www.iasp-pain.org/GlobalYear/CancerPain/>

[4] Kwon JH. Overcoming barriers in cancer pain management. J Clin Oncol 2014; 32(16): 1727-1733.

[5] Fisch MJ, Lee JW, Weiss M, Wagner LI, Chang VT, Cella D, Manola JB, Minasian LM, McCaskill-Stevens W, Mendoza TR, Cleeland CS. Prospective, observational study of pain and analgesic prescribing in medical oncology outpatients with breast, colorectal, lung, or prostate cancer. J Clin Oncol 2012; 30(16): 1980-1988

[6] Stockler MR, Wilcken NR. Why is management of cancer pain still a problem? J Clin Oncol 2012; 30(16): 1907-1908.

[7] Al-ZahraniO, Eldali A, Al-Shahri MZ. Prevalence and severity of pain in cancer patients in an outpatient palliative care setting in Saudi Arabia. Qatar Med J 2014; 2014(1): 38-45.

[8] Wells N, Pasero C, McCaffery M. Chapter 17: Improving the quality of care through pain assessment and management. In: Patient Safety and Quality: An Evidence-Based Handbook for Nurses. (). Hughes RG, ed. Rockville, (MD): Agency for Healthcare Research and Quality (US). 2008

[9] [No authors listed]. Cancer pain relief. Geneva:World Health Organization, 1986

[10] Albaqawi HM, Maude P, Shahwan-Akl L. Saudi Arabian nurses' knowledge and attitudes regarding pain management: survey results using the KASRP. Int J Health Sci Res 2016; 6(12): 150-164. 
[11] Samarkandi OM. Knowledge and attitudes of nurses toward pain management. Saudi J Anaesth 2018; 12(2): 220-226.

[12] Alqahtani M, Jones LK. Quantitative study of oncology nurses' knowledge and attitudes towards pain management in Saudi Arabian hospitals. Eur J Oncol Nurs 2015; 19(1): 44-49.

[13] Al-Wassia RK. Knowledge and attitudes of nurses working at King Abdulaziz University Hospital toward cancer pain management. Open J Nurs 2016; 6: 274-281.

[14] Fallatah SM. Pain knowledge and attitude survey among health-care professionals at a university hospital in Saudi Arabia. Saudi J Med Med Sci 2017; 5(2): 155-159.

[15] EyobT, Mulatu A, Abrha H. Knowledge and attitude towards pain management among medical and paramedical students of an Ethiopian University. J Pain Relief 2013; 3(1): 127.

[16] Latchman J. Improving pain management at the nursing education level: evaluating knowledge and attitudes. J Adv Pract Oncol 2014; 5(1): 10-16.

[17] Kaki AM. Medical students' knowledge and attitude toward cancer pain management in Saudi Arabia. Saudi Med J 2011; 32(6): 628-632.

[18] McMillan SC, Tittle M, Hagan S, Laughlin J, Tabler RE. Knowledge and attitudes of nurses in veterans' hospitals about pain management in patients with cancer. Oncol Nurs Forum 2000; 27(9):1415-1423.

[19] McMillan S, Tittle M, Hagan S, Small B. Training pain resource nurses: changes in their knowledge and attitudes. Oncol Nurs Forum 2005; 32(4): 835-842.

[20] Ung A, SalamonsonY,HuW, Gallego G. Assessing knowledge, perceptions and attitudes to pain management among medical and nursing students: a review of the literature. $\mathrm{Br}$ J Pain 2016; 10(1): 8-21.

[21] Al-Khawaldeh OA, Al-Hussami M, Darawad M. Knowledge and attitudes regarding pain management among Jordanian nursing students. Nurse Educ Today 2013; 33(4): 339-345.

[22] Rahimi-Madiseh M, Tavakol M, Dennick R. A quantitative study of Iranian nursing students' knowledge and attitudes towards pain: implication for education. Int J Nurs Pract 2010; 16(5): 478-483.

[23] Tufail N, Zaeem K, Ghani M, Afshan S, Ayesha. Association of the knowledge of nurses about the pain management with their attitude towards cancer patients. Anaesth Pain Int Care 2017; 21(2): 166-169.

[24] Hroch J, VanDenKerkhof EG, Sawhney M, Sears N, GedckeKerr L. Knowledge and attitudes about pain management among Canadian nursing students. Pain Manag Nurs 2019; 20(4): 382-389.

[25] Gadallah MA, Hassan AM, Shargawy SA. Undergraduate nursing students' knowledge and attitude regarding pain management of children in Upper Egypt. J Nurs Educ Pract 2017; 7(6): 100-107. 


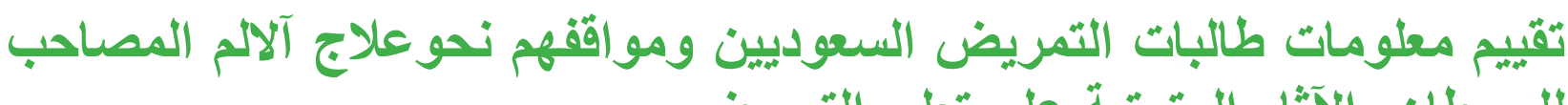

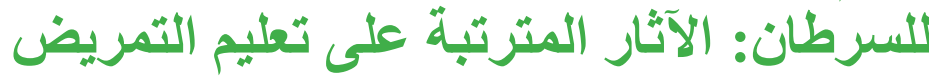

$$
\begin{aligned}
& \text { ضحى يوسف وزق } \\
& \text { قسم التمريض الباطني الجر/حي }
\end{aligned}
$$

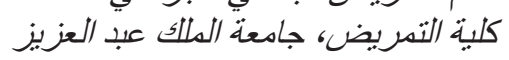

$$
\begin{aligned}
& \text { جلة ـ المدلكة العربية السعودية العلية }
\end{aligned}
$$

المستخلص. علاج الألم غير الفعال مشكلة كبيرة يو اجهها العديد من مرضى السرطان. هناك نقص في التركيز على علاج

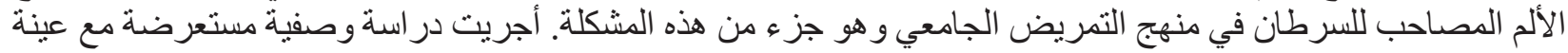

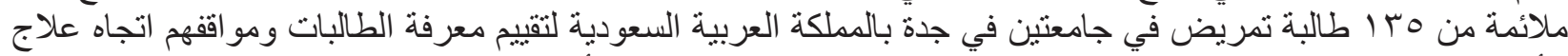

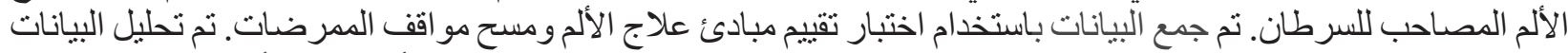

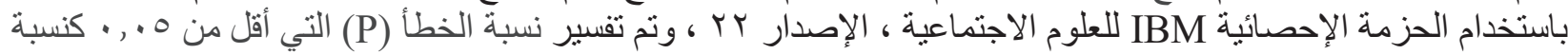

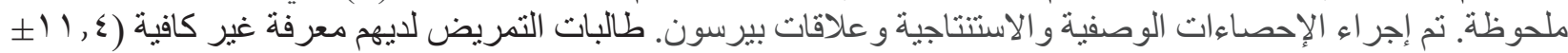

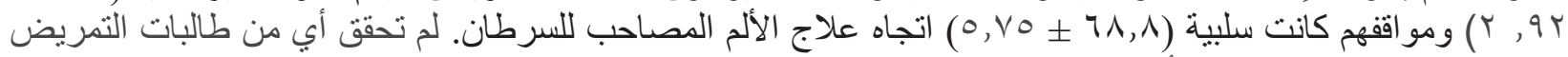

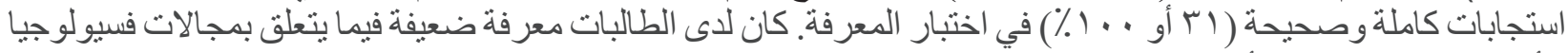

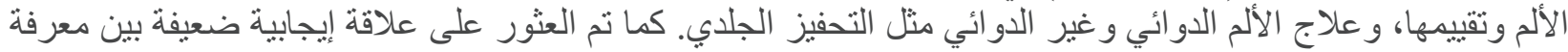

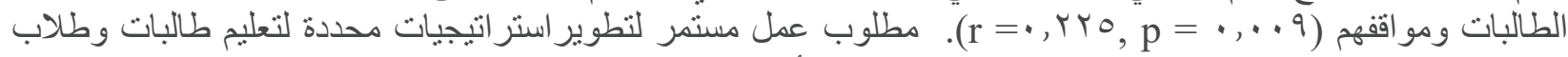

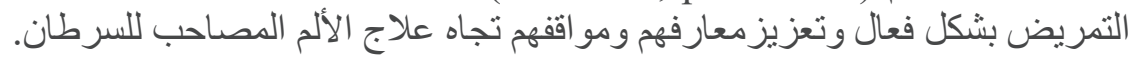

